This is an Accepted Manuscript of an article published by Taylor \& Francis in Journal of Sports Sciences on 04/03/2020, available online:

http://www.tandfonline.com/10.1080/02640414.2020.1734311.

\title{
Key somatic variables associated with, and differences between the 4 swimming strokes
}

\author{
Alan M. Nevill a, Yassine Negra b, Tony D. Myers c, Senda Sammoud b and Helmi \\ Chaabene d \\ a Faculty of Education, Health and Wellbeing, University of Wolverhampton, Wolverhampton, UK; b \\ Research Unit (UR17JS01) «Sports Performance, Health \& Society», Higher Institute of Sport and \\ Physical Education of Ksar Saîd, Universite de la Manouba, Manouba, Tunisia; c Sport and Health, \\ Newman University, Birmingham, UK; d Division of Training and Movement Sciences, Research \\ Focus Cognitive Sciences, University of Potsdam,Potsdam, Germany
}

Contact

Alan M. Nevill a.m.nevill@wlv.ac.uk

University of Wolverhampton Faculty of Education, Health and Wellbeing,

Walsall Campus,

Gorway Road,

Walsall,

WS1 3BD

\section{Abstract}

This study identified key somatic and demographic characteristics that benefit all swimmers and, at the same time, identified further characteristics that benefit only specific swimming strokes. Three hundred sixty-three competitive-level swimmers (male [ $=202]$; female [ $n=161]$ ) participated in the study. We adopted a multiplicative, allometric regression model to identify the key characteristics associated with $100 \mathrm{~m}$ swimming speeds (controlling for age). The model was refined using backward elimination. Characteristics that benefited some but not all strokes were identified by introducing stroke-by-predictor variable interactions. The regression analysis revealed 7 "common" characteristics that benefited all swimmers suggesting that all swimmers benefit from having less body fat, broad shoulders and hips, a greater arm span (but shorter lower arms) and greater forearm girths with smaller relaxed arm girths. The 4 stroke-specific characteristics reveal that backstroke swimmers benefit from longer backs, a finding that can be likened to boats with longer hulls also travel faster through the water. Other stroke-by-predictor variable interactions (taken together) identified that butterfly swimmers are 
characterized by greater muscularity in the lower legs. These results highlight the importance of considering somatic and demographic characteristics of young swimmers for talent identification purposes (i.e., to ensure that swimmers realize their most appropriate strokes).

Keywords: Swim speed, talent identification, limb dimensions, ratios, allometric models, log-linear regression

\section{Introduction}

Many clubs and national federations invest substantial resources into the identification of young gifted or talented athletes to ensure that the most promising receive high-quality coaching and training conditions (Williams \& Reilly, 2000). Anthropometric characteristics are known to be an important factor in identifying talented athletes at an early age (Morais et al., 2012; Morais, Silva, Marinho, Lopes, \& Barbosa, 2017). The fact that anthropometric characteristics are influenced less by training compared with other physical-fitness attributes highlights the importance of investigating and/or studying anthropometrics when trying to identify early athletic potential.

Recently, a number of studies have reported strong associations between human physical characteristics and sports performance (Geladas, Nassis, \& Pavlicevic, 2005; Negra et al., 2016; Nevill, Oxford, \& Duncan, 2015; Sammoud, Nevill, Negra, Bouguezzi, Chaabene, \& Hachana, 2018a; Sammoud, Nevill, Negra, Bouguezzi, Chaabene, \& Hachana, 2018b; Sammoud, Nevill, Negra, Bouguezzi, Chaabene, \& Hachana, 2019). These studies highlighted the importance of determining the association between anthropometric characteristics and sports performance in order to engage children in appropriate long-term athletic development programmes.

In swimming, talent identification and development processes play a crucial role in the pursuit of excellence across a long-term career. In this regard, anthropometric characteristics are arguably one of the most important factors in swimmers achieving a high-performance level in their careers (Geladas et al., 2005; Lätt et al., 2010). While, these studies identified important characteristics associated with swimming performance, they did this for each stroke separately (Jurimae, Cicchella, Latt, Purge, Leppik, \& Jurimae, 2007; Nevill et al., 2015; Sammoud et al. 2018a; Sammoud et al. 2018b; Sammoud et al., 2019, 2020). For example, Sammoud et al. (2018a) revealed that $100-\mathrm{m}$ butterfly speed performance was strongly and positively associated with the segment length ratio [(arm-span)/(forearm-length) and girth ratio (calf-girth)/(anklegirth), rather than the whole-body size characteristics. More recently, Sammoud et al. (2018b) reported positive associations between 100-m breaststroke performance and limb-girth ratio (girth ratio = forearm girth/wrist girth) in young swimmers whose mean age was $12 \pm 1.2$ years. 
Nevill et al. (2015) revealed that lean body mass was the singularly most important whole-body characteristic associated with front crawl swim speeds and that having greater limb segment length ratios [i.e., arm ratio $=($ lower arm $) /($ upper arm $)$; foot-toleg ratio $=($ foot $) /($ lower-leg) $]$ were key to personal best swim speeds. Lätt et al. (2010) indicated that anthropometrical factors explained $45.8 \%$ of $100-\mathrm{m}$ front crawl swimming performance in male swimmers aged 15 years. Santos et al. (2012) found a positive association $(r=0.68)$ between the arm muscle area and the propulsive force of the arm in young swimmers (9-14 years old), with the increased arm muscle area contributing to a greater capacity for strength. Another study by Moura et al (2014) showed a positive association between the propulsive force of the arm and body height $(r=0.34 ; p=0.013)$, arm span $(r=0.29 ; p=0.042)$, sitting height $(r=0.36 ; p=0.009)$, $\%$ body fat $(r=0.33 ; p=0.016)$, lean body mass $(r=0.34 ; p=0.015)$ and arm muscle area $(r=0.31 ; p=0.026)$. Likewise, Fritzdorf et al. (2009) reported that taller and bigger swimmers with longer stroke lengths can produce more force per-stroke. In contrast, smaller swimmers whose stroke lengths are shorter will invariably utilize a higher stroke rate when competing.

Bond, Goodson, Oxford, Nevill, and Duncan (2015) suggested that anthropometric variables accounted for $63.8 \%$ of 100 -m freestyle swimming's total variance in a 13year-old male and female swimmers. Similarly, Geladas et al. (2005) examined the association between anthropometric measures and swimming performance in male and female swimmers aged 12-to-14 years. They showed that upper extremity length was associated with a $100-\mathrm{m}$ freestyle performance in males while upper extremity length, height, and hand-length were significantly related to performance in females. Recently, the main anthropometric determinants of backstroke swimming performance have been examined in young swimmers aged 13-14 years (Sammoud et al., 2019). The authors revealed that forearm girth, as well as arm relaxed girth, is among the main backstroke performance indicators. More recently, Sammoud et al. (2020) indicated that length ratio $=([$ height/leg length] $)$, foot length and ankle girth, biacromial breadth (shoulder width) and \% of body fat were associated with 100-m front crawl mean swimming speed performance.

As far as we are aware, however, no study has attempted to identify the key somatic and demographic characteristics that are common for all strokes, but at the same time, to identify other characteristics that benefit only specific/individual strokes. Therefore, the purpose of this article was to explore which key somatic and demographic characteristics are common to all swimmers and, in addition, to identify further characteristics that benefit only specific strokes, i.e. that are "stroke specific".

\section{Methods}




\section{Participants}

In total three hundred sixty-three competitive-level swimmers (male [ $\mathrm{n}=202]$; female $[n=161]$ ) participated to this investigation (Front-crawl swimmers: $n=74$, Butterfly swimmers: $n=167$, Backstroke swimmers: $n=63$, and Breaststroke swimmers: $n$ = 59) (demographic details described in Table 1). The majority of swimmers $(n=145)$ contributed to just one swimming-stroke cohort. Eighty-three swimmers $(n=83)$ contributed to two swimming-stroke cohorts (on separate occasions), sixteen swimmers $(n=16)$ contributed to 3 and just one swimmer $(n=1)$ contributed to all 4 swimming-stroke cohorts. We acknowledge that some of these data/details have been published previously, but crucially in isolation (Butterfly Sammoud et al., 2018a; Breaststroke 2018b; Backstroke Sammoud et al., 2019). 
Table 1. Descriptive statistics (means $\pm S D$ ) of the swimming performance, demographic and somatic measurements by sex and stroke.

Variables Male Female

\begin{tabular}{|c|c|c|c|c|c|c|c|c|c|c|c|c|c|c|c|c|}
\hline Strokes & Breaststroke & SD & Butterfly & SD & Backstroke & SD & Front Crawl & SD & Breaststroke & SD & Butterfly & SD & Backstroke & SD & Front Crawl & SD \\
\hline $\mathrm{N}$ & 39 & & 103 & & 30 & & 30 & & 20 & & 64 & & 33 & & 44 & \\
\hline $100 \mathrm{~m}$ time $(\mathrm{s})$ & 97.7 & 13.5 & 79.1 & 13.2 & 77.2 & 8.8 & 54.8 & 3.3 & 95.4 & 9.5 & 81.8 & 11.2 & 79.5 & 5.0 & 62.0 & 4.5 \\
\hline Speed $\left(m \cdot s^{-1}\right)$ & 1.04 & 0.14 & 1.30 & 0.22 & 1.31 & 0.17 & 1.83 & 0.11 & 1.06 & 0.10 & 1.24 & 0.16 & 1.26 & 0.08 & 1.62 & 0.12 \\
\hline Age (yrs) & 11.5 & 1.3 & 13.1 & 2.8 & 14.0 & 0.6 & 19.0 & 3.8 & 12.1 & 1.0 & 13.6 & 2.6 & 13.0 & 1.2 & 15.9 & 2.7 \\
\hline Maturity offset (yrs) & -2.33 & 1.10 & -1.02 & 2.28 & -0.87 & 0.78 & 3.56 & 2.46 & 0.04 & 1.00 & 1.06 & 1.83 & 0.82 & 0.96 & 3.02 & 1.77 \\
\hline Body Mass (kg) & 41.5 & 9.5 & 50.0 & 14.2 & 48.7 & 12.3 & 73.2 & 9.7 & 46.0 & 8.6 & 49.3 & 9.2 & 49.1 & 7.1 & 62.5 & 9.2 \\
\hline Stature $(\mathrm{cm})$ & 149.9 & 10.4 & 158.3 & 12.7 & 157.2 & 11.6 & 177.8 & 6.5 & 155.9 & 8.0 & 157.9 & 9.0 & 158.8 & 7.4 & 168.9 & 9.0 \\
\hline Body Fat (\%) & 16.8 & 5.5 & 16.6 & 5.2 & 17.6 & 5.7 & 12.9 & 2.8 & 19.0 & 4.3 & 18.6 & 3.7 & 18.2 & 3.9 & 18.0 & 4.4 \\
\hline Sitting height $(\mathrm{cm})$ & 74.4 & 5.8 & 78.6 & 7.1 & 77.8 & 6.8 & 90.7 & 4.3 & 76.4 & 7.9 & 79.0 & 6.6 & 79.7 & 3.9 & 85.2 & 5.0 \\
\hline Upper limb length $(\mathrm{cm})$ & 69.3 & 5.3 & 73.3 & 6.2 & 72.6 & 5.6 & 82.6 & 3.5 & 72.0 & 4.4 & 73.1 & 4.5 & 74.1 & 4.4 & 78.6 & 5.0 \\
\hline Upper arm length $(\mathrm{cm})$ & 29.0 & 2.2 & 30.8 & 2.9 & 30.5 & 2.5 & 34.9 & 2.1 & 30.4 & 2.0 & 31.0 & 2.3 & 31.2 & 2.2 & 33.3 & 2.6 \\
\hline Lower arm length $(\mathrm{cm})$ & 23.2 & 1.9 & 24.3 & 2.1 & 23.9 & 1.6 & 27.2 & 1.8 & 23.7 & 1.7 & 24.2 & 1.7 & 24.3 & 1.7 & 25.7 & 1.9 \\
\hline Hand length $(\mathrm{cm})$ & 18.0 & 1.6 & 19.0 & 1.6 & 18.9 & 1.3 & 21.1 & 1.1 & 18.7 & 1.0 & 18.9 & 1.0 & 19.0 & 0.9 & 19.9 & 1.2 \\
\hline Lower limb length $(\mathrm{cm})$ & 81.6 & 6.1 & 85.9 & 6.6 & 85.5 & 5.6 & 93.4 & 4.2 & 85.0 & 5.0 & 86.4 & 5.7 & 86.9 & 5.0 & 92.1 & 5.2 \\
\hline Thigh length $(\mathrm{cm})$ & 38.9 & 5.8 & 41.4 & 3.1 & 41.6 & 3.1 & 44.3 & 2.3 & 42.0 & 2.2 & 42.8 & 3.4 & 42.9 & 3.0 & 45.5 & 3.9 \\
\hline Leg length $(\mathrm{cm})$ & 42.0 & 3.4 & 44.2 & 3.5 & 43.7 & 2.8 & 48.2 & 2.7 & 43.4 & 2.5 & 43.7 & 2.7 & 44.1 & 2.5 & 46.1 & 2.9 \\
\hline Foot length $(\mathrm{cm})$ & 25.1 & 2.2 & 26.2 & 1.8 & 26.1 & 1.6 & 27.8 & 1.3 & 25.5 & 1.1 & 25.2 & 1.1 & 25.3 & 1.1 & 26.3 & 1.5 \\
\hline Arm relaxed Girth $(\mathrm{cm})$ & 23.0 & 3.0 & 24.8 & 3.8 & 24.4 & 3.2 & 30.7 & 2.9 & 23.8 & 2.3 & 24.6 & 2.2 & 24.1 & 2.0 & 28.1 & 2.0 \\
\hline Forearm Girth $(\mathrm{cm})$ & 21.1 & 1.9 & 22.7 & 3.0 & 22.2 & 2.4 & 27.5 & 1.9 & 21.5 & 1.5 & 21.9 & 1.6 & 21.8 & 1.5 & 24.3 & 2.0 \\
\hline Wrist Girth $(\mathrm{cm})$ & 14.7 & 1.1 & 15.5 & 1.4 & 15.4 & 1.3 & 17.4 & 0.9 & 15.4 & 2.3 & 15.0 & 0.8 & 15.2 & 0.8 & 16.8 & 4.9 \\
\hline Thigh Girth (cm) & 43.9 & 4.5 & 46.8 & 5.4 & 46.5 & 4.9 & 52.9 & 5.0 & 46.1 & 5.6 & 47.7 & 4.4 & 47.3 & 3.8 & 51.8 & 4.3 \\
\hline Calf Girth (cm) & 30.3 & 3.1 & 32.3 & 3.4 & 32.4 & 3.1 & 36.7 & 2.0 & 30.7 & 3.0 & 31.9 & 2.6 & 32.4 & 2.3 & 34.9 & 2.8 \\
\hline Grith ankle (cm) & 20.5 & 1.8 & 21.2 & 1.8 & 21.2 & 2.1 & 23.1 & 1.3 & 20.5 & 1.5 & 20.7 & 1.2 & 20.9 & 1.1 & 22.4 & 1.4 \\
\hline Biacromial breadth & 41.5 & 3.9 & 43.8 & 3.5 & 43.4 & & 48.2 & 2.4 & 43.3 & 2.3 & 43.7 & & 43.9 & & 45.3 & 2.4 \\
\hline$(\mathrm{cm})$ & & & & & & 2.6 & & & & & & 2.1 & & 2.0 & & \\
\hline Biiliac breadth $(\mathrm{cm})$ & 24.4 & 2.4 & 26.2 & 2.7 & 25.7 & 2.3 & 29.0 & 2.2 & 25.7 & 2.4 & 26.5 & 2.3 & 26.4 & 2.2 & 28.6 & 2.3 \\
\hline $\operatorname{Arm}$ span $(\mathrm{cm})$ & 150.4 & 13.5 & 161.1 & 15.6 & 160.6 & 13.1 & 184.5 & 9.8 & 158.3 & 9.7 & 160.6 & 10.6 & 160.7 & 10.2 & 173.4 & 11.6 \\
\hline
\end{tabular}


All participants were involved in five to six training sessions per week (4000 \pm 1000 $m$ per session; $8 \pm 1$ hour per-week). In addition, the training session included the four-stroke. Written informed parental consent and participant assent were obtained prior to the start of the study. All youth athletes and their parents/legal representatives were informed about the experimental protocol and its potential risks and benefits before the commencement of the research project. The study was approved by the local Ethics Institutional Review Committee for the ethical use of human subjects at Ksar Saïd University, Tunisia.

\section{Anthropometric and somatic measurements}

All the anthropometric measurements were taken by one trained anthropometrist assisted by a recorder in accordance with standardized procedures of the international society for the advancement of kinanthropometry (ISAK) (Stewart, Marfell-Jones, Olds, \& de Ridder, 2011) (Table 1).

Testing was carried out in a standardized order after proper calibration of the measuring instruments. Each swimmer's height $(\mathrm{m})$ and body-mass $(\mathrm{kg})$ were assessed to the nearest $0.1 \mathrm{~cm}$ and $0.1 \mathrm{~kg}$, using a SECA stadiometer and a SECA weighing scale (SECA Instruments Ltd, Hamburg, Germany), respectively. Skinfolds measurements (in millimetres) were taken on the right-hand side of the body at two sites (the triceps and the subscapular) using Harpenden skinfold calipers (Harpenden Instruments, Cambridge, UK). Skinfold data, alongside the skinfold equation of Slaughter et al. (1988), were used to estimate the body-fat mass and fat-free mass. The following limb-lengths, girths and breadths were assessed using a large sliding caliper and a non-stretchable tape measure via direct measures using landmarks techniques: arm span, upper-limb length, upper-arm length, lower-arm length, hand lengths, lower-limb length, thigh length, leg length, foot length, arm-relaxed girth, forearm girth, wrist girth, thigh girth, calf girth, ankle girth, biacromial (shoulder width in layman's terms) and biiliocristal-breadths (hip width in layman's terms).

Upper arm length was measured from landmarks placed to acromiale and dactylion while athletes stood in the erect position. Upper arm length was determined as the distance between the marked acromiale and radiale landmarks. The lower-arm length was measured by calculating the distance between the radiale and stylion landmarks. For the hand length, the measure was taken as the shortest distance from the marked midstylion line to the dactylion. Lower limb length was determined by subtracting sitting height from standing height. Thigh length was determined as the distance between the marked trochanterion and tibiale lateral landmarks. Leg length was measured as the distance from the height of the tibiale lateral to the top of the box (or the floor). Foot length was determined as the distance from the Akropodion (i.e., the tip of the longest toe which may be the first or second phalanx) to the Pternion (i.e., most posterior point on the calcaneus of the foot). Arm-relaxed girth was measured at the marked level of 
the mid-acromiale-radiale. The tape was positioned perpendicular to the long axis of the arm.

Forearm girth was taken at the maximum girth of the forearm distal to the humeral epicondyles. Wrist girth measurement is taken distal to the styloid processes. It is the minimum girth in this region. Thigh girth measure was taken at the marked midtrochanterion-tibiale-lateral site. Calf girth was defined as the maximum girth of the calf taken at the marked medial calf skinfold site. Ankle girth was defined as the minimum girth of the ankle taken at the narrowest point superior to the Sphyrion tibiale. Biacromial breadths were determined as the distance between the most lateral points of the acromion processes. Biiliocristal breath was defined as the distance between the most lateral points on the iliac crests. All somatic measures were recorded twice and the mean scores were retained for the statistical analysis.

\section{Swimming performance quantification}

The swimming times and/or speeds expressed in seconds and metres per second $\left(\mathrm{m} . \mathrm{s}^{-1}\right)$, respectively, were adopted as our measures of swimming performance. Swimming performance was recorded in a $25-\mathrm{m}$ swimming pool. The average speed was calculated as the ratio between distances swam and the total time recorded at this distance $\left(\mathrm{m}^{-1} \mathrm{~s}^{-1}\right)$. The performance times were measured with electronic timing (Omega, Switzerland) and were obtained for all swimmers from official results published by the Tunisian swimming Federation during the Winter National Championships. Water temperature was kept between 25 and 28 degrees, as determined by Fédération Internationale De Natation (FINA, 2014).

Descriptive statistics (means $\pm S D$ ) of all the swimming performance, demographic and somatic measurements by sex and stroke are given in Table 1.

\section{Statistical methods}

To identify the optimal demographic and somatic measurements, including body mass $(\mathrm{M})$, stature $(\mathrm{H})$, percentage body fat (BF\%) and limb dimensions (lengths and girths) (LD), associated with $100 \mathrm{~m}$ swimming speeds (SS) $\left(\mathrm{m} . \mathrm{s}^{-1}\right)$ in all four strokes having controlled for age, we adopted the following multiplicative model with allometric bodysize components similar to those used to model the front-crawl swim speeds adopted by Nevill et al. (2015).

$$
\begin{aligned}
\mathrm{SS}\left(\mathrm{m} \cdot \mathrm{s}^{-1}\right)=\mathrm{a} \cdot(\mathrm{M})^{\mathrm{k} 1} \cdot(\mathrm{H})^{\mathrm{k} 2} \cdot(\mathrm{BF} \%)^{\mathrm{k} 3} \cdot \Pi\left(\mathrm{LD}_{\mathrm{i}}\right)^{\mathrm{ki}} \\
\cdot \exp \left(\mathrm{b} \cdot \mathrm{age}+\mathrm{c} \cdot \mathrm{age}^{2}+\mathrm{d} \cdot \mathrm{MO}\right) \cdot \varepsilon .
\end{aligned}
$$


where "a" is a constant and $\pi\left(\operatorname{LD}_{i}\right)^{k_{i}}(i=4,5, \ldots$,$) represents the product of limb$ segment-dimensions raised to the power $\mathrm{k}_{\mathrm{i}}$; with $\mathrm{i}=4$ being the Sitting height, 5 = Upper limb length, 6 = Upper arm length, 7 = Lower arm length, etc. (see list of variables in Table 1) and MO is the maturity offset (Mirwald, Baxter-Jones, Bailey, \& Beunen, 2002). This model has the advantages of having proportional body-size components and the flexibility of a non-linear quadratic in age within an exponential term that will ensure that the $100 \mathrm{~m}$ swim speeds will always remain non-negative irrespective of the child or adolescent's age (see Figure 1). Note that the multiplicative error ratio " $\varepsilon$ " assumes the error will increase in proportion to the child's swim-speed performance.

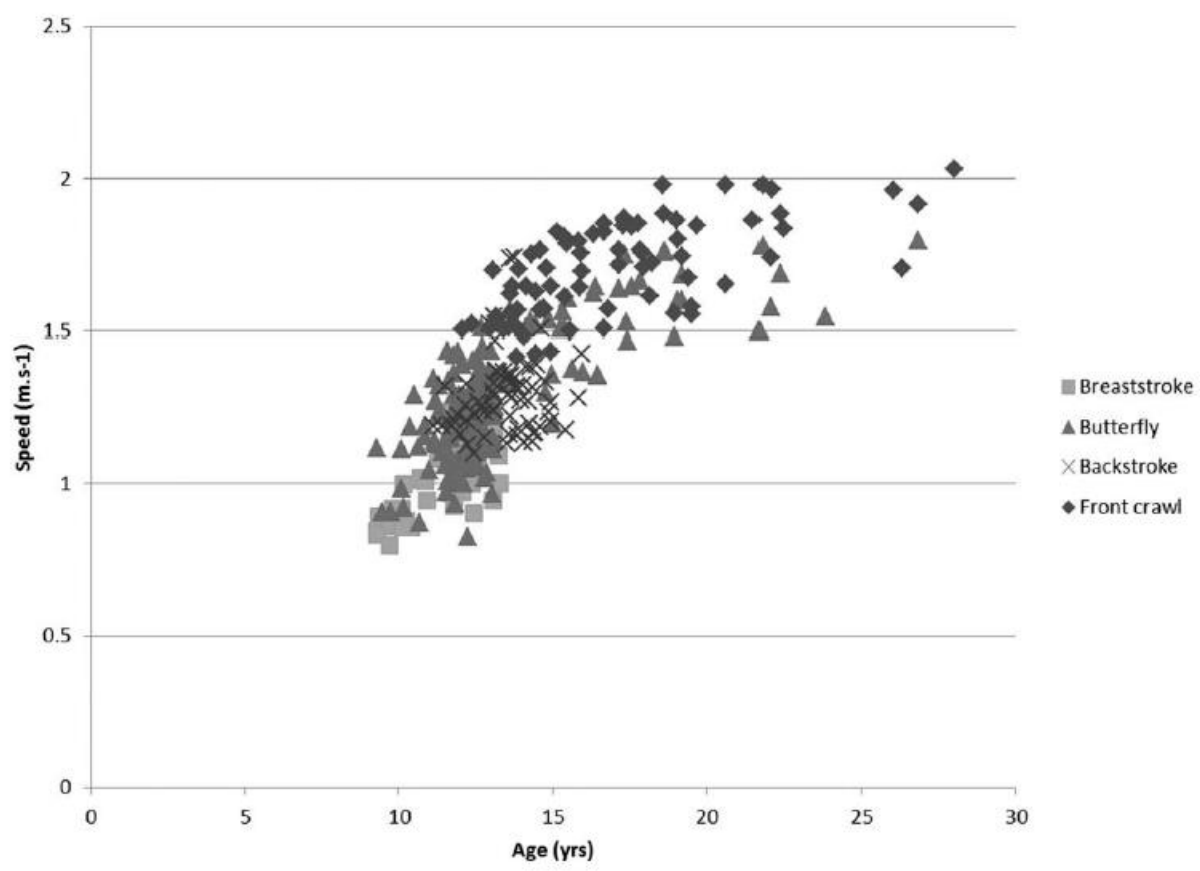

Figure 1. The relationship between $100-\mathrm{m}$ swim speeds and age by stroke.

The model (Equation (1)) can be linearized with a log transformation. A linear regression on $\ln (\mathrm{SS})$ (In = natural logarithms) can then be used to estimate the unknown parameters of the log-transformed model:

$$
\begin{aligned}
\operatorname{Ln}(S S)= & \ln (a)+k_{1} \cdot \ln (M)+k_{2} \cdot \ln (H)+k_{3} \cdot \ln (B F \%) \\
& +\sum^{k_{i}} \cdot \ln \left(L_{i}\right)+b \cdot a g e+c \cdot a^{2}+d \cdot M O+\ln (\varepsilon) .
\end{aligned}
$$

Having fitted the saturated model (all available demographic, somatic and body size variables), an appropriate "parsimonious" model can be obtained using "backward elimination" Draper and Smith, 1998 in which at each step the least important (nonsignificant) body size and limb segment dimensions variable is dropped from the current model. Further categorical or group differences within the population, e.g. sex 
and swim stroke, can be explored by allowing the constant intercept parameter "In(a)" in Equation (2) to vary for each group (by introducing them as fixed factors and associated interactions within an ANCOVA). The significance level was set at $P<0.05$. Practical importance (meaningfulness) was assessed by reporting effect sizes (partial eta squared $=\eta^{2}$ ) as recommended by Winter, Grant, and Nevill (2014)

Given that some swimmers contributed to more than one cohort (with measurements taken on different occasions), the data can be treated as repeated measurements with a hierarchical structure. For this reason, we repeated the above analysis using multilevel modelling with the statistical software MLwin that allows the different swimmers to be treated as the level 2 hierarchy and their different performance speeds to be at the level 1 hierarchy (see Watts, Coleman, \& Nevill, 2012).

\section{Results}

The parsimonious solution to the backward elimination regression analysis of logtransformed swim speed ( $\mathrm{Ln}(\mathrm{SS})$ ) resulted in the following multiple regressions model (Table 2):

Table 2. The parsimonious solution to the backward elimination regression analysis to predict log-transformed swim speeds ( $\mathrm{Ln}(\mathrm{SS})$ ) given by Equation (2).

\begin{tabular}{|c|c|c|c|c|c|c|}
\hline Predictor variables & $\mathrm{B}$ & SE & $\mathrm{t}$ & Sig & Lower Bound & Upper Bound \\
\hline Front crawl-intercept Ln(a) & -2.856 & .784 & -3.644 & .000 & -4.397 & -1.314 \\
\hline Breaststroke ALn(a) & -.421 & .910 & -.463 & .644 & -2.212 & 1.369 \\
\hline Butterfly ALn(a) & -1.644 & .824 & -1.996 & .047 & -3.264 & -.023 \\
\hline Backstroke ALn(a) & -2.499 & .966 & -2.587 & .010 & -4.399 & -.599 \\
\hline Male ALn(a) & .033 & .009 & 3.717 & .000 & .016 & .051 \\
\hline Ln(Body Fat) & -.089 & .018 & -4.891 & .000 & -.125 & -.053 \\
\hline Ln(Lower arm length) & -.247 & .078 & -3.178 & .002 & -.399 & -.094 \\
\hline Ln(Arm relaxed girth) & -.272 & .100 & -2.716 & .007 & -.469 & -.075 \\
\hline Ln(Forearm girth) & .409 & .132 & 3.099 & .002 & .149 & .669 \\
\hline Ln(Biacromial breadth) & .434 & .094 & 4.602 & .000 & .249 & .620 \\
\hline Ln(Biiliac breadth) & .171 & .050 & 3.410 & .001 & .072 & .269 \\
\hline Ln(Arm span) & .327 & .087 & 3.761 & .000 & .156 & .498 \\
\hline Front crawl * age & .002 & .003 & .569 & .569 & -.004 & .008 \\
\hline Breaststroke * age A & .052 & .011 & 4.822 & .000 & .031 & .074 \\
\hline Butterfly * age $A$ & .012 & .004 & 2.811 & .005 & .004 & .020 \\
\hline Backstroke * age A & .000 & .009 & .048 & .962 & -.018 & .019 \\
\hline Front crawl * Ln(Sitting height) & .148 & .197 & .749 & .455 & -.240 & .535 \\
\hline Breaststroke * Ln(Sitting height) A & -.317 & .231 & -1.376 & .170 & -.771 & .136 \\
\hline Butterfly * Ln(Sitting height) A & .108 & .216 & .502 & .616 & -.316 & .533 \\
\hline Backstroke Ln(Sitting height) A & .492 & .291 & 1.690 & .092 & -.081 & 1.065 \\
\hline Front crawl * Ln(Calf girth) A & -.175 & .160 & -1.090 & .276 & -.490 & .140 \\
\hline Breaststroke * Ln(Calf girth) A & .009 & .230 & .037 & .970 & -.444 & .461 \\
\hline Butterfly * Ln(Calf girth) A & .689 & .187 & 3.685 & .000 & .321 & 1.057 \\
\hline Backstroke * Ln(Calf girth) A & .199 & .265 & .751 & .453 & -.323 & .721 \\
\hline Front crawl * Ln(Ankle girth) & .004 & .173 & .024 & .981 & -.337 & .345 \\
\hline Breaststroke * Ln(Ankle girth) A & .254 & .271 & .936 & .350 & -.280 & .787 \\
\hline Butterfly * Ln(Ankle girth) A & -.526 & .208 & -2.532 & .012 & -.935 & -.117 \\
\hline Backstroke * Ln(Ankle girth) A & -.180 & .234 & -.771 & .441 & -.641 & .280 \\
\hline
\end{tabular}

Values are means standard errors of estimate. Female front crawl swimmers were used as the reference group (baseline intercept measure $\operatorname{Ln}(\mathrm{a}))$ and other swim stroke groups were compared with it, indicated by $(A \operatorname{Ln}(a))$.

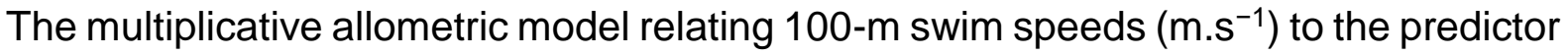
variables found the percentage body fat $\mathrm{Ln}(\mathrm{BF} \%)$ as the only "whole-body" predictor of Ln(SS) (body mass and stature were dropped from the analysis). Six other 
predictors in addition to the percentage body fat ( $\mathrm{Ln}(\mathrm{BF} \%))$ were found to be significantly associated with $\mathrm{Ln}(\mathrm{SS})$, all found to be commonly associated with the four strokes. These were Ln(arm span), Ln(biacromial breadth), Ln(biiliac breadth), Ln(forearm girth), that were positively associated with SS, and Ln(lower arm length) and $\mathrm{Ln}$ (relaxed arm girth) that were both negatively associated with SS performance.

Four other predictor variables were also found to be strongly associated with $\operatorname{Ln}(\mathrm{SS})$, BUT these associations varied significantly with the 4 different strokes. These were identified by introducing stroke-by-predictor variable interactions (see statistical methods). The 4 significant interactions were "stroke-by-age" $\left(F_{3,335}=9.068\right.$; $\left.\eta^{2}=0.075, P<0.001\right)$, "stroke-by-sitting height" $\left(F_{3,335}=4.12 ; ; \eta^{2}=0.036, P=0.007\right)$, "stroke-by-calf girth" ( $\left.F_{3,335}=6.48 ; ; \eta^{2}=0.055, P<0.001\right)$, and "stroke-by-ankle girth" $\left(F_{3,335}=4.59 ; ; \eta^{2}=0.040, P=0.004\right)$ (see Table 2). Our allometric model also detected a significant sex difference with male swimmers able to swim $3.3 \%$ faster than female swimmers (Table 2). The adjusted coefficient of determination, adjusted $\mathrm{R}^{2}$ for the fitted multiplicative allometric model was $88.3 \%$ with the log-transformed error ratio being 0.068 or $7.08 \%$, having taken antilogs.

As stated in the methods, given that some of the swimmers contributed to more than one cohort, the hierarchical or repeated-measures nature of these data was reanalysed using the multilevel modelling statistical software MLwin. The results are given in Table 3. 
Table 3. The parsimonious solution to the backward elimination regression analysis to predict log-transformed swim speeds (Ln(SS)) using multilevel modelling (MLwin).

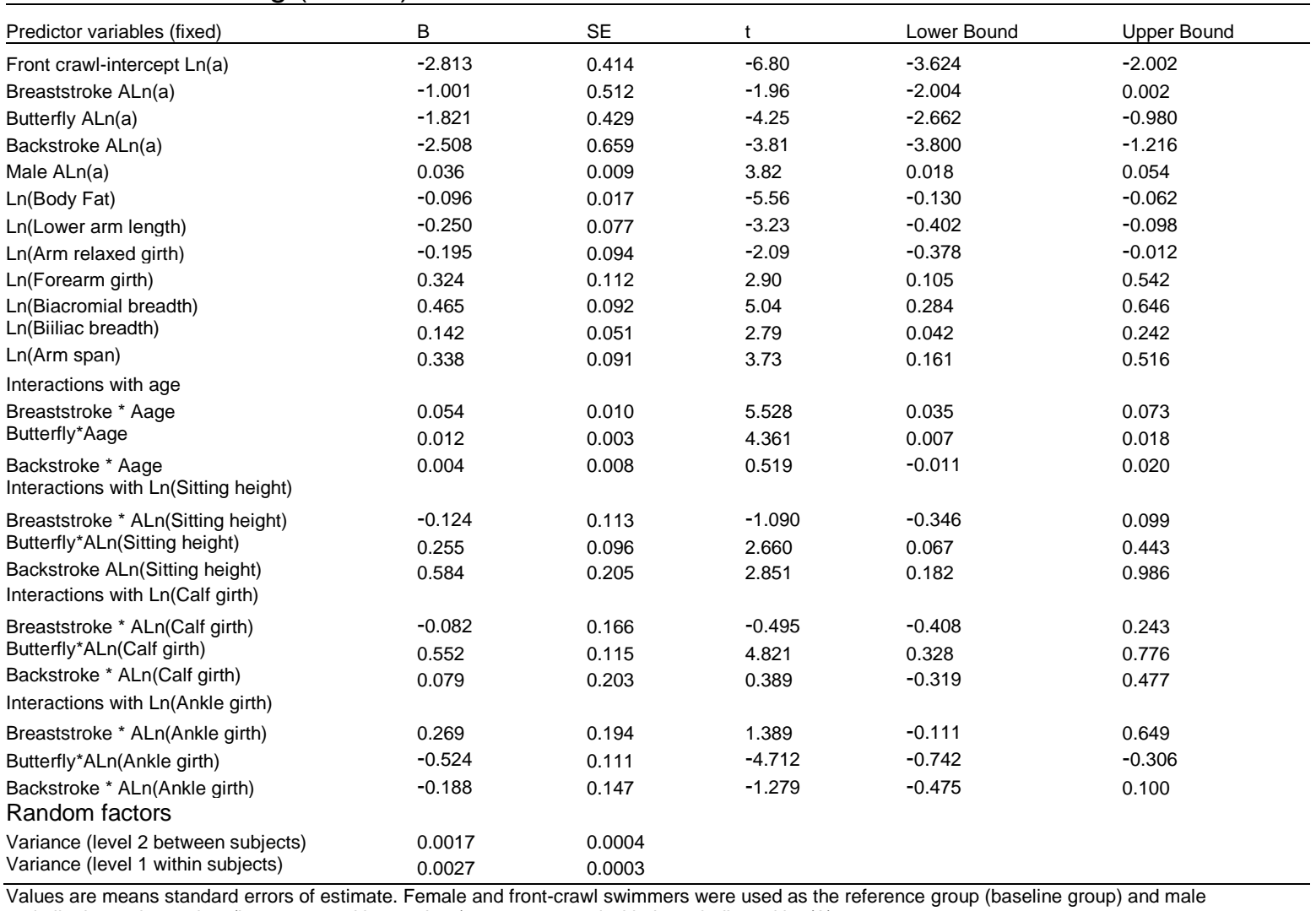

and all other swim strokes (intercepts and interactions) were compared with them, indicated by (A)

\section{Discussion}

There is compelling evidence that anthropometric and somatic characteristics play a key role in the early identification of talented/gifted athletes (Issurin, 2017). This is because such characteristics are more genetically determined and less trainable than most physical fitness attributes (Issurin, 2017). For instance, it has been established that anthropometrics such as body length (e.g., height, limb lengths and feet) are strongly determined by genetics (level of inherence of 70\%) (Bouchard, Malina, \& Perusse, 1997; Szopa, Mleczko, \& Zychowska, 1999). The present study used an allometric modelling approach and ANCOVA to identify the optimal anthropometric, somatic and demographic characteristics (as covariates) associated with 100-m

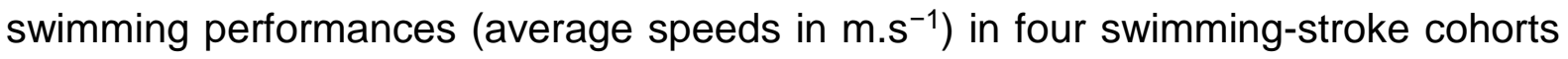
(back stroke, breast stroke, butterfly and front crawl) based in Tunisia. We recognise that some swimmers contributed to more than one cohort, so when we re-analysed the data using multilevel modelling that takes these repeated measurements into account, the results were remarkably similar (see Table 3 vs. Table 2) and our conclusions remained the same. For the sake of simplicity, we shall focus our discussion on the first of the two analyses (Table 2). 
The results identified seven predictor variables that were common to all strokes (see Table 1) together with another 4 characteristics that would appear to benefit some strokes significantly more than others (identified by stroke-by-predictor variable interactions). The total explained variance of these predictor variables was $88.3 \%$ (adjusted $\mathrm{R}^{2}$ ) although we acknowledge that the majority of the effect sizes were relatively modest, between small and moderate (http://imaging.mrccbu.cam.ac.uk/statswiki/FAQ/effectSize)

Of the seven "common" predictor variables, percentage body fat $(\mathrm{Ln}(\mathrm{BF} \%))$ was the single most important "whole-body" size characteristic $(B=-0.089, S E=0.018 ; P$ $<0.001)$. Unsurprisingly, having a lower BF\% benefits all 4 strokes. Stature and body mass did not contribute significantly to the parsimonious allometric model, suggesting that the advantage of having longer levers and/or greater girth dimensions was "limb specific" rather than a more general whole-body advantage.

The four positive "common" predictor variables associated with swim speed were Ln(arm span), Ln(biiliac breadth) or hip width in layman's terms, Ln(biacromial breadth) or shoulder width in layman's terms, and Ln(forearm girth). The two negative "common" characteristics associated with swim speed were Ln(lower-arm length) and Ln(arm-relaxed girth). Taken together, swimmers from all four strokes appear to benefit from broad shoulders and hips, a greater arm span (but with relatively short lower arms) and greater forearm girths but smaller relaxed arm girths.

Having taken anti-logs, the two common "arm length" predictors can be combined for form an "arm span"-by-"lower arm" ratio given by the ratio = (arm span) $)^{\wedge} 0.327 /$ (lower arm length)^ 0.247 (see Table 2 for exponents) that highlights the advantage of having a greater arm span but also highlights a possible disadvantage of having a too greater lower-arm length. Similarly, the two common arm girth predictors can be combined to form a common "arm-girth" ratio given by the ratio $=(\text { forearm girth })^{\wedge} 0.409 /($ relaxed arm girth)^ 0.272 (see Table 2 for the exponents). This ratio was also identified by Sammoud et al. (2019) as key to backstroke swimming performance. The authors suggested that the "arm girth" ratio was possibly reflecting a measure of muscularity, i.e., with the muscularity component resulting from the flexed vs. non-flexed girth ratio.

However, from a talent identification point of view, the 4 stroke-by-predictor variable interactions provide the most illuminating new insights. The significant stroke-by-sitting height interaction reveals that backstroke swimmers have the longest sitting heights, a finding that is in direct contrast to the breaststroke swimmers who have the shortest sitting heights. Sammoud et al. (2019) had already reported a similar finding when identifying key somatic variables associated with young backstroke swimmers, likening the sitting height of a swimmer with the length of a boat's hull. It is well known that boats with longer hulls travel faster through the water (Charles, 2010). The analogy implied here to backstroke swimming performance is that the longer sittingheight component of the skeleton will also reflect the benefits of a longer boat's hull 
when travelling through the water (although this analogy is not unanimously accepted since backstroke, being a rotational stroke along the longitudinal axis, and breaststroke, being a rotational stroke along the transverse axis, have fundamentally different dynamics).

The stroke-by-calf girth interaction together with the stroke-by-ankle girth interaction can also be considered operating together. Inspection of the two interactions in Table 2 reveals that the stroke associated with greatest calf girth is also the stroke with the smallest ankle girth, namely the butterfly. Again having taken antilogs, butterfly swimmers are characterized by having the greatest "calf girth"-to-"ankle girth" ratio, given by (calf girth)^ $0.515 /$ (ankle girth) ${ }^{\wedge} 0.522$. We can speculate that this ratio is likely to reflect the greater muscularity in the lower leg associated with butterfly swimmers. However, the ratio is specific to butterfly swimmers alone and cannot be considered as an important indicator of swimmers from the other three strokes.

The regression analysis also identified a significant stroke-by-age interaction (see Table 2). In our original model specification, see the statistical methods section (Equation (1)), we anticipated a curvilinear association between swim speed and age, justified by the apparent curvature observed in Figure 1 and the necessity to include the quadratic age terms in Equation (1). In reality, much of the apparent curvature can be explained by the different age slopes observed for the different strokes, with the steepest slope observed in breaststroke swimmers and the shallowest slope identified with the front crawl swimmers, see Figure 1.

\section{Conclusion}

In summary, the present study revealed 7 "common" characteristics that benefit all swimmers, and 4 other characteristics that benefit some but not all swimmers. Taken together, the 7 "common" characteristics suggest that all swimmers benefit from having less body fat, broad shoulders and hips, a greater arm span (but shorter lower arms) and greater forearm girths with smaller relaxed arm girths. The 4 strokespecific characteristics reveal that backstroke swimmers benefit from longer backs, a finding that can be likened to boats with longer hulls also travel faster through the water. The stroke-by-calf girth and the stroke-by-ankle girth interactions taken together identified butterfly swimmers with having the greater calf girths but also the smaller ankle girths, i.e., faster butterfly swimmers are characterized by greater muscularity in the lower legs. These results highlight the importance of considering key somatic characteristics of young swimmers for talent identification purposes (i.e., to ensure that swimmers realize their most appropriate strokes).

\section{Disclosure statement}

No potential conflict of interest was reported by the authors. 


\section{References}

Bond, D., Goodson, L., Oxford, S. W., Nevill, A. M., \& Duncan, M. J. (2015). The association between anthropometric variables, functional movement screen scores and $100 \mathrm{~m}$ freestyle swimming performance in youth swimmers. Sports, 3, 1-11.

Bouchard, C., Malina, R. M., \& Perusse, L. (1997). Genetics of fitness and physical performance. Champaign: Human Kinetics.

Charles, D. (2010). http://www.wavetrain.net/boats-a-gear/74-crunching-numberswhy-longer-is-faster.

Draper, N. R., \& Smith, H. (1998). Applied regression analysis (vol. 326). John Wiley \& Sons.

Federation Internationale De Natation (FINA). Talent identification programmes. 2014 [cited 18 September 2014]. Available from: http://www.fina.org/.

Fritzdorf, S.G., Hibbs, A., \& Kleshnev, V. (2009). Analysis of speed, stroke rate, and stroke distance for world-class breaststroke swimming. Journal of Sports Science, 27, 373-378.

Geladas, N., Nassis, G. P., \& Pavlicevic, S. (2005). Somatic and physical traits affecting sprint swimming performance in young swimmers. International Journal of Sports Medicine, 26, 139-144.

Issurin, V. B. (2017). Evidence-based prerequisites and precursors of athletic talent: A review. Sports Medicine, 47(10), 1993-2010.

Jurimae, J., Haljaste, K., Cicchella, A., Latt, E., Purge, P., Leppik, A., \& Jurimae, T. (2007). Analysis of swimming performance from physical, physiological, and biomechanical parameters in young swimmers. Pediatric Exercise Science, 19, 7081.

Lätt, E., Jürimäe, J., Mäestu, J., Purge, P., Rämson, R., Haljaste, K., ... Jürimäe, T. (2010). Physiological, biomechanical and anthropometrical predictors of sprint swimming performance in adolescent swimmers. Journal of Sports Science and Medicine, 9, 398-404.

Mirwald, R. L., Baxter-Jones, A. D., Bailey, D. A., \& Beunen, G. P. (2002). An assessment of maturity from anthropometric measurements. Medicine \& Science in Sports \& Exercise, 34(4), 689-694.

Morais, J. E., Jesus, S., Lopes, V., Garrido, N., Silva, A., Marinho, D., \& Barbosa, T. M. (2012). Linking selected kinematic, anthropometric and hydrodynamic variables to young swimmer performance. Pediatric Exercise Science, 24, 649-664.

Morais, J. E., Silva, A. J., Marinho, D. A., Lopes, V. P., \& Barbosa, T. M. (2017). Determinant factors of long-term performance development in young swimmers. International Journal of Sports and Physiology Performance, 12, 198-205. 
Moura, T., Raphael, R.D., \& Marcos, S. (2014). Height and body compositon determine arm propulsive force in youth swimmers independant of maturation stage. Journal of Human Kinetics, 42277-42284.

Negra, Y., Chaabene, H., Hammami, M., Khlifa, R., Gabett, T., \& Hachana, Y. (2016). Allometric scaling and age related differences in change of direction speed performances of young soccer players. Science and Sports, 31, 19-26.

Nevill, A. M., Oxford, S. W., \& Duncan, M. J. (2015). Optimal body size and limb length ratios associated with 100-m personal-best swim speeds. Medicine and Science in Sports and Exercise, 47, 1714-1718.

Sammoud, S., Negra, Y., Chaabene, H., Bouguezzi, R., Attia, A., Granacher, U., \& Nevill, A. M. (2020). Key anthropometric variables associated with front-crawl swimming performance in youth swimmers: An allometric approach. Journal of Strength and Conditioning Association. (In press).

Sammoud, S., Nevill, A. M., Negra, Y., Bouguezzi, R., Chaabene, H., \& Hachana, Y. (2018a). Allometric associations between body size, shape, and 100-M butterfly speed performance. Journal of Sports Medicine and Physical Fitness, 58(5), 630637.

Sammoud, S., Nevill, A. M., Negra, Y., Bouguezzi, R., Chaabene, H., \& Hachana, Y. (2018b). 100-meter breaststroke swimming performance in youth swimmers: The predictive value of anthropometrics. Pediatric Exercise Science, 30(3), 393-401.

Sammoud, S., Nevill, A. M., Negra, Y., Bouguezzi, R., Chaabene, H., \& Hachana, Y. (2019). Key somatic variables in young backstroke swimmers. Journal of Sports Science, 37(10), 1162-1167.

Santos, M.A., M.L., de Castro Melo, W.V., Veronese, D.C.A., \& Costa, M.C. (2012). Estimate of propulsive force in front crawl swimming in young athletes. Open Access Journal of Sports Medicine, 3, 115-120

Slaughter, M. H., Lohman, T. G., Boileau, R. A., Horswill, C. A., Stillman, R. J., VanLoan, M. D., \& Bemben, D. A. (1988). Skinfold equations for estimation of body fatness in children and youth. Human Biology, 60, 709-723.

Stewart, A., Marfell-Jones, M., Olds, T., \& de Ridder, H. (2011). International standards for anthropometric assessment (pp. 57-72). Lower Hutt, New Zealand: ISAK

Szopa, J., Mleczko, E., \& Zychowska, M. (1999). Possibilities of determination of genetic conditionings of somatic and functional traits on the backgrounds of family studies. Journal of Human Kinetics, 2, 21-36.

Watts, A. S., Coleman, I., \& Nevill, A. M. (2012). The changing shape characteristics associated with success in world-class sprinters. Journal of Sports Sciences, 30(11), 1085-1095.

Williams, A. M., \& Reilly, T. (2000). Talent identification and development in soccer. Journal of Sports Science, 18(9), 657-667. 
Winter, E. M., Grant, A., \& Nevill, A. M. (2014). Metrics of meaningfulness as opposed to sleights of significance. Journal of Sports Science, 32(10), 901-902. 